\title{
Tác động của quản trị công ty đến cấu trúc vốn: Nghiên cứu thực nghiệm từ các công ty niêm yết trên thị trường chứng khoán Việt Nam \\ The impact of corporate governance on capital structure: Experimental research from listed companies in VietNam stock market
}

\author{
Nguyễn Văn Thuận ${ }^{1}$, Nguyễn Thị Thu Thủy ${ }^{2}$ \\ ${ }^{1,2}$ Trường Đại học Tài chính - Marketing, Việt Nam \\ *Tác giả liên hệ, Email: thuan.nv@ufm.edu.vn
}

THÔNG TIN

DOI: 10.46223/HCMCOUJS.

econ. vi.15.2.235.2020

Ngày nhận: 20/03/2020

Ngày nhận lại: 11/04/2020

Duyệt đăng: 22/04/2020

Tù khóa:

cấu trúc vốn, phương pháp

GMM, quản trị công ty,

TTCK Việt Nam

Keywords:

capital structure, GMM

method, Corporate

governance, Vietnam stock market

\section{TÓM TÁT}

\begin{abstract}
Nghiên cứu này kiểm chứng tác động của quản trị công ty với cấu trúc vốn của các công ty niêm yết trên thị trường chứng khoán Việt Nam giai đoạn 2008-2018. Sử dụng phương pháp GMM cho mẫu dữ liệu gồm 479 công ty. Kết quả cho thấy có mối quan hệ cùng chiều giữa thành viên hội đồng quản trị độc lập (TVHDQTDL), quy mô hội đồng quản trị (QMHDQT), tỷ suất lợi nhuận trên tổng tài sản (ROA), tài sản cố định (TSCD) với cấu trúc vốn của doanh nghiệp. Mối quan hệ ngược chiều của quy mô công ty (QMCT) với cấu trúc vốn. Tác giả không tìm thấy mối quan hệ giữa nữ tổng giám đốc điều hành (CEONU) và cấu trúc vốn.
\end{abstract}

\begin{abstract}
This study examines the impact of corporate governance on the capital structure of firms listed on Vietnam's stock market during the 2008-2018 period. Using the GMM method to analyze data collected from 479 companies, the results show a positive correlation among independent members of the Board of Directors, BOD size, Return on Assets (ROA), fixed assets with firm's capital structure and a negative correlation between firm size and its capital structure. The findings did not reveal any relationship between female directors and firm's capital structure.
\end{abstract}

\section{Giới thiệu}

Cấu trúc vốn đóng vai trò quan trọng đến tình hình tài chính của công ty (Heng, Azrbaijani, \& San, 2012) về cách mà công ty lựa chọn giữa nợ và vốn chủ sở hữu để tài trợ cho 
các hoạt động kinh doanh của mình. Chọn kết hợp sai cấu trúc vốn có thể dẫn đến khó khăn tài chính. Adams và Mehran (2003) cho rằng quản trị công ty là một hoạt động liên quan đến các cấu trúc vốn và quy trình dẫn đến việc tạo ra giá trị cổ đông bằng cách quản lý các công việc của công ty. Các vấn đề của công ty nên được quản lý để đảm bảo bảo vệ lợi ích tập thể và cá nhân của các bên liên quan của công ty. Các quyết định về cấu trúc vốn là một trong những vấn đề cấp thiết nhất mà ban lãnh đạo các công ty phải giải quyết. Mặc dù, có nhiều nghiên cứu của Nadeem và Zongjun (2011); Buvanendra, Sridharan, và Thiyagarajan (2017); Robert và Rabih (2018); Mai và Truong (2018) về thực tiễn quản trị công ty và cấu trúc vốn nhưng kết quả các nghiên cứu không đồng nhất với nhau do các quan điểm lý thuyết khác nhau, lựa chọn phương pháp và đo lường các biến cũng khác nhau, do quan điểm mâu thuẫn về sự tham gia của hội đồng quản trị trong việc ra quyết định và bối cảnh bản chất của các công ty cá nhân (Shafana, 2016). Nghiên cứu ảnh hưởng của mối quan hệ thực nghiệm giữa quản trị công ty và cấu trúc vốn của công ty phần lớn chưa được khám phá. Mục tiêu chính trong nghiên cứu này xác định tác động của quản trị công ty đến cấu trúc vốn.

\section{Các quan điểm về quản trị công ty và cấu trúc vốn}

\subsection{Các quan điểm về quản trị công ty}

Shleifer và Vishny (1997) định nghĩa quản trị công ty (QTCT) bằng cách nói rằng QTCT xử lý các vấn đề để đảm bảo các nhà đầu tư của doanh nghiệp nhận được lợi ích từ các khoản đầu tư của mình. Một khái niệm tương tự được đề xuất bởi Caramanolis - Cotelli (1995), người xem QTCT là việc xác định phân chia vốn/tài sản giữa những người trong công ty (bao gồm ban giám đốc, tổng giám đốc, hoặc tổ chức, cá nhân khác liên quan đến ban quản lý công ty) và các nhà đầu tư bên ngoài.

\subsection{Các quan điểm về cấu trúc vốn}

Cấu trúc vốn là cách mà một công ty tài trợ chính bằng cách kết hợp nợ dài hạn, nợ ngắn hạn và vốn chủ sở hữu (Ross, Westerfield, \& Jaffe, 2005). Nó cho thấy cách một công ty tài trợ cho hoạt động tổng thể và tăng trưởng của mình bằng cách sử dụng các nguồn vốn khác nhau. Cấu trúc vốn của các công ty thay đổi theo quy mô, loại hình và một số đặc điểm khác như tuổi của công ty, quy mô công ty, cơ cấu tài sản, lợi nhuận, tăng trưởng công ty, rủi ro và thanh khoản của công ty (Al-Najjar \& Taylor, 2008).

\section{Cơ sở lý thuyết và giả thuyết nghiên cứu về mối quan hệ giữa quản trị công ty và cấu trúc vốn}

\subsection{Quy mô hội đồng quản trị và cấu trúc vốn}

Từ quan điểm quản lý cho thấy Chủ tịch hội đồng quản trị là một trong những yếu tố quan trọng nhất của cơ chế quản trị công ty trong việc giám sát hiệu quả và hoạt động thích hợp của công ty. Nó đóng một vai trò quan trọng trong việc giảm thiểu sự thất bại của công ty (Chancharat, Krishnamurti, \& Tian, 2012). Nó chịu trách nhiệm theo dõi các hoạt động chính và thông qua các quyết định chiến lược. Các nghiên cứu trước cho kết quả 2 chiều liên quan đến mối quan hệ giữa quy mô hội đồng quản trị và cấu trúc vốn. Một mặt, Berger, Ofek, và Yermack (1997) cho thấy rằng quy mô hội đồng quản trị có ảnh hưởng tiêu cực đến cấu trúc 
vốn. Tương tự, Robert và Rabih (2018) tìm thấy mối quan hệ tiêu cực giữa quy mô hội đồng quản trị và cấu trúc vốn. Mặt khác, Jensen (1986) nhận thấy rằng các công ty có quy mô hội đồng quản trị càng lớn thì có cấu trúc vốn càng cao hơn so với các công ty có quy mô ban đầu nhỏ hơn và cho thấy rằng các công ty có hội đồng quản trị lớn có nhiều khả năng sử dụng nhiều khoản nợ hơn vốn chủ sở hữu.

H1: Quy mô hội đồng quản trị có mối quan hệ cùng chiều với cấu trúc vốn của công ty

\subsection{Thành viên hội đồng quản trị độc lập và cấu trúc vốn}

Thành viên hội đồng quản trị độc lập cần phải có kiến thức hoặc thông tin, có thể cho phép công ty có mức độ tài chính cao hơn cấu trúc vốn, sự có mặt của các thành viên hội đồng quản trị độc lập dự kiến sẽ dẫn đến đòn bẩy tài chính cao (Berger et al., 1997). Theo Detthamrong, Chancharata, và Vithessonthi (2017) bổ sung, nhiệm kỳ của thành viên hội đồng quản trị độc lập không được dài hơn chín năm, bắt đầu từ ngày bổ nhiệm lần đầu vị trí của thành viên độc lập. Umawadee, Nongnit, và Chaiporn (2017) đã tìm thấy kết quả là thành viên hội đồng quản trị độc lập có tác động ngược chiều với cấu trúc vốn trái lại Nadeem và Zongjun (2011) thì có thấy thành viên hội đồng quản trị độc lập có tác động cùng chiều với cấu trúc vốn.

H2: Thành viên hội đồng quản trị độc lập có mối quan hệ cùng chiều với cấu trúc vốn

\subsection{Nũ tổng giám đốc điều hành và cấu trúc vốn}

Có một niềm tin rằng nhà quản lý nữ sẽ có thể nâng cao hiệu quả của hội đồng quản trị. Nhà quản lý nữ có thể hỗ trợ quản lý của công ty thông qua sử dụng các kỹ năng và kiến thức về quản lý nhân sự, truyền thông và quan hệ công chúng nhiều hơn đối tác nam giới (Zelechowski \& Bilimoria, 2004). Strøm, D'Espallier, và Mersland (2014) thấy rằng CEO nữ trong hội đồng quản trị của các giám đốc sẽ cho kết quả hoạt động tài chính tốt hơn, dựa trên mẫu của các công ty ở 73 quốc gia trong giai đoạn 1998-2008. Huang, Li, Meschke, và Guthrie (2015) cho thấy nhiều công ty ở các nước tiên tiến có đòn bẩy thấp, sự hiện diện của CEO nữ trong các công ty có đòn bẩy thấp có thể thúc đẩy họ có đòn bẩy cao hơn. Vì các công ty ở các nước đang phát triển nói chung có nhiều hạn chế về mặt tài chính so với các nước phát triển.

H3: CEO nũ có mối quan hệ cùng chiều với cấu trúc vốn

\subsection{Quyền kiêm nhiệm và cấu trúc vốn}

Nếu Giám đốc điều hành cũng là Chủ tịch của hội đồng quản trị, chi phí đại diện sẽ tăng nhiều hơn bởi vì khả năng giám sát của hội đồng đến các Giám đốc điều hành bị giảm (Dey, Engel, \& Liu, 2011) cho rằng, các doanh nghiệp sẽ hoạt động kém hiệu quả hơn khi $\mathrm{CEO}$ và chủ tịch HĐQT là hai cá nhân khác nhau. Nadeem và Zongjun (2011) cho thấy quyền kiêm nhiệm có tác động ngược chiều với cấu trúc vốn. Quyền kiêm nhiệm có lẽ đã làm tăng đáng kể sức mạnh của Giám đốc điều hành so với của hội đồng quản trị, do đó có thể giảm hiệu quả của các cơ chế kiểm soát của cơ cấu quản trị công ty (Simpson \& Gleason, 1999) và dẫn đến dưới hoặc vượt mức đòn bẩy, phụ thuộc vào sự ưa thích rủi ro của Giám đốc điều hành.

H4: Chủ tịch hộ đồng quản trị kiêm nhiệm tổng giám đốc có mối quan hệ ngược chiều với cấu trúc vốn của công ty 


\subsection{Quyền sở hũu tập trung và cấu trúc vốn}

Lý thuyết đại diện cho thấy rằng quyền sở hữu tập trung của công ty sẽ dẫn đến giám sát hiệu quả hơn. Sở hữu tập trung làm giảm thiểu xung đột lợi ích giữa các nhà quản lý và chủ sở hữu (Suto, 2003). Cấu trúc sở hữu của một công ty cũng có thể ảnh hưởng đến cấu trúc vốn như nó có hàm ý cho các mối quan hệ đại diện trong công ty (Claessens \& Fan, 2002; Wiwattanakantang, 2001). Tuy nhiên, các công ty có sự tập trung quyền sở hữu cao có một loại vấn đề đại diện khác. Đó là, có thể có một xung đột lợi ích cổ đông lớn và cổ đông thiểu số. Wiwattanakantang (2001) cho thấy rằng quyền sở hữu tập trung có tác động tích cực đến đòn bẩy tài chính. Nadeem và Zongjun (2011) cũng cho thấy kết quả quyền sở hữu tập trung có tác động cùng chiều với cấu trúc vốn.

\section{H5: Sở hũu tập trung có mối quan hệ cùng chiều với cấu trúc vốn}

\subsection{Quy mô của ban kiểm soát và cấu trúc vốn}

Ban kiểm soát có trách nhiệm tư vấn lựa chọn kiểm toán viên bên ngoài, quản lý kiểm soát, tạo sự tự tin trong tính chính xác, độ tin cậy và chất lượng của tài chính (Anderson, Mansi, $\&$ Reeb, 2004). Những nghiên cứu trước đây như của Chen, Cheung, Stouraitis, và Wong (2005) cho thấy rằng kiểm toán báo cáo tài chính cung cấp thông tin quan trọng về rủi ro tín dụng của công ty đối với các nhà cung cấp vốn. Thông tin có thể dẫn đến phê duyệt tín dụng nghiêm ngặt, do đó ảnh hưởng đến một cơ hội nhận khoản vay. Hiệu quả của ban kiểm soát sẽ cho phép các doanh nghiệp tiếp cận tốt hơn với nguồn tài chính bên ngoài khi cần thiết. Do đó, có thể hy vọng ban kiểm soát sẽ có mối liên kết với đòn bẩy. Tuy nhiên, mối quan hệ có thể là tích cực hoặc tiêu cực phụ thuộc vào mức độ của đòn bẩy. Một mặt, ban kiểm soát có thể cho phép công ty tăng đòn bẩy của nó do thông tin tốt hơn và tin cậy được nhận thức bởi các thị trường (các chủ nợ và nhà đầu tư). Mặt khác, nó có thể hạ thấp đòn bẩy tài chính của công ty nếu mức độ đòn bẩy hiện tại được coi là quá cao.

H6: Quy mô ban kiểm soát có mối quan hệ cùng chiều với cấu trúc vốn

\section{Phương pháp nghiên cứu}

\subsection{Phương pháp tiếp cận}

Đề tài được tiếp cận theo hướng lược khảo các nghiên cứu trước để tìm ra khe hỏng của nghiên cứu sau đó nghiên cứu được tiếp cận bằng cách kết hợp giữa phương pháp định tính và định lượng. Trong nghiên cứu định lượng tác giả sử dụng phương pháp ước lượng GMM theo nghiên cứu của Arellano và Bond (1991) để xử lý tính nội sinh. Tác giả sử dụng phương pháp hồi quy tổng quát GMM (Generalized method of moments). GMM có 2 dạng ước lượng phổ biến được sử dụng là Dif-GMM và Sys-GMM, nghiên cứu lựa chọn sử dụng Sys-GMM cho 479 công ty niêm yết trên sàn HOSE và HNX trong giai đoạn 10 năm từ 2008-2018 của các ngành nghề chủ yếu như vật liệu xây dựng, sản xuất kinh doanh, thực phẩm, sản xuất kinh doanh, thủy sản, Xây dựng, công nghệ viễn thông, năng lượng, điện và khí.

\subsection{Mô hình nghiên cúu}

\section{Tác động của quản trị công ty lên cấu trúc vốn}


Mô hình nghiên cứu được xây dựng dựa trên các công trình của Umawadee và cộng sự (2017); Nadeem và Zongjun (2011); S. Buvanendra và cộng sự (2017); Robert và Rabih (2018); Mai và Truong (2018).

$$
\begin{gathered}
L E V_{i t}=\propto+\beta_{1} \mathrm{QMHĐQT}+\beta_{2} T V H Ð Q T D L+\beta_{3} C E O N U+\beta_{4} C E O K N+\beta_{5} T O P 5+ \\
\beta_{6} Q M B K S+\beta_{7} T U O I+\beta_{8} Q M C T+\beta_{9} T S C D+\beta_{10} T T R+\beta_{11} R O A+\beta_{12} N G A N H+\mu i t
\end{gathered}
$$

Trong đó: LEV: Đòn bẩy tài chính, QMHĐQT: Quy mô hội đồng, TVHĐQTDL: Thành viên hội đồng quản trị độc lập, CEONU: Nữ tổng giám đốc điều hành, CEOKN: Quyền kiêm nhiệm (Chủ tịch kiêm nhiệm tổng Giám đốc), TOP5: Sở hữu tập trung, QMBKS: Quy mô ban kiểm soát, Tài sản cố định: TSCD, TUOI: Tuổi của công ty, TTR: Tăng trưởng, QMCT: Quy mô công ty, ROA: tỷ suất lợi nhuận trên tổng tài sản, ngành của công ty: NGANH, $\alpha$ : Là số hạng tung độ gốc, $\mu$ it: Là sai số của mô hình theo i và t.

\section{Bảng 1}

\begin{tabular}{|c|c|c|}
\hline Biến & Khái niệm & Cách đo lường \\
\hline \multicolumn{3}{|l|}{ Biến phụ thuộc } \\
\hline$L E V$ & Đòn bẩy tài chính & Tỷ lệ nợ/Tổng tài sản \\
\hline$Q M H Ð Q T$ & Quy mô HĐQT & Ln (số lượng thành viên trong HĐQT) \\
\hline$T V H Đ Q T D L$ & Thành viên HĐQT độc lập & $\begin{array}{l}\text { Số lượng thành viên HĐQT độc lập/ Tổng } \\
\text { sồ thành viên HĐQT }\end{array}$ \\
\hline$C E O K N$ & Quyền kiêm nhiệm & $\begin{array}{l}\text { Biến giả nhận giá trị là } 1 \text { nếu có Chủ tịch } \\
\text { kiêm nhiệm tông Giám đốc và ngược lại } \\
\text { thì nhận giá trị là } 0\end{array}$ \\
\hline TOP5 & Sở hữu tập trung & $\begin{array}{l}\text { Tổng phần trăm sở hữu của các cổ phần cổ } \\
\text { đông lớn và cổ đông nội bộ trong công ty } \\
\text { Ln (tổng số thành viên trong BKS) }\end{array}$ \\
\hline$Q M B K S$ & Quy mô ban kiểm soát & Biến giả nhận giá trị là 1 nếu có nữ tổng \\
\hline CEONU & Nữ tổng giám đốc điều hành & $\begin{array}{l}\text { giám đốc điều hành ngược lại nhận giá trị } \\
\text { là } 0\end{array}$ \\
\hline
\end{tabular}

Tóm tắt các biến nghiên cứu 


\begin{tabular}{|c|c|c|}
\hline Biến & Khái niệm & Cách đo lường \\
\hline Các biến kiểm soát & & \\
\hline$Q M C T$ & Quy mô công ty & Ln (tổng tài sản) \\
\hline$\widetilde{T S C D}$ & Tài sản cố định & Tổng tài sản cố định / Tổng tài sản \\
\hline$T T R$ & Tăng trưởng & $\begin{array}{l}\text { (Giá trị sổ sách tổng tài sản năm nay - giá } \\
\text { trị sồ sách tổng tài sản năm trước)/ Giá trị } \\
\text { sồ sách tổng tài sản năm trước }\end{array}$ \\
\hline TUOI & Tuổi của công ty & $\begin{array}{l}\text { Ln (năm nghiên cứu - năm thành lập công } \\
\text { ty) }\end{array}$ \\
\hline$R O A$ & Lợi nhuận trên tổng tài sản & Lợi nhuận sau thuế / Tổng tài sản \\
\hline NGANH & Ngành của công ty & $\begin{array}{l}\text { Biến giả (1-9), } 1 \text { là dầu khí, } 2 \text { là vật liệu co } \\
\text { bản, } 3 \text { là hàng tiêu dùng, } 4 \text { là y tế, } 5 \text { là dịch } \\
\text { vụ tiêu dùng, } 6 \text { là viễn thông } 7 \text { là các dịch } \\
\text { vụ hạ tầng, } 8 \text { là công nghiệp, } 9 \text { là công } \\
\text { nghệ }\end{array}$ \\
\hline
\end{tabular}

Nguồn: Kết quả phân tích dữ liệu của nhóm nghiên cứu

\subsection{Phương pháp nghiên cúu}

\subsubsection{Dũ liệu nghiên cúu}

Để thực hiện nghiên cứu thực nghiệm theo mô hình trên, các công ty được chọn để kiểm định quản trị công ty và cấu trúc vốn của doanh nghiệp là các công ty niêm yết trên sàn HOSE và $H N X$ trong giai đoạn 10 năm từ 2008-2018 để đảm bảo tính đại diện, có thể phản ánh được tình hình hoạt động của TTCK VN. Tác giả chọn số lượng công ty niêm yết trên hai sàn là 479 công ty (5.269 quan sát) vì số lượng các công ty niêm yết không đều nhau nên tác giả áp dụng chọn mẫu theo phương pháp phi ngẫu nhiên (phương pháp chọn mẫu thuận tiện), tác giả trừ ra tất cả các công ty thuộc ngành Tài chính, Ngân hàng và Bảo hiểm vì các công ty thuộc ngành này có loại hình kinh doanh đặc thù riêng, có các quy định về quản trị doanh nghiệp cũng như các quy định hiện hành về lập và trình bày các báo cáo tài chính không hoàn toàn đồng nhất với các công ty thuộc các ngành còn lại trong toàn bộ mẫu.

\subsubsection{Phuong pháp GMM (Generalized Method of Moments)}

Nghiên cứu sử dụng phương pháp hồi quy định lượng GMM mà GMM có 2 dạng ước lượng thay thế lẫn nhau là ước lượng Dif-GMM và Sys-GMM. Moment điều kiện thêm vào trong ước lượng Sys-GMM được sử dụng tương ứng với mô hình Levels, với công cụ là độ trễ khác nhau của các biến nội sinh Blundell và Bond (1998) cho rằng, ước lượng Sys-GMM cho kết quả tốt hơn ước lượng Dif-GMM, bởi vì công cụ trong mô hình Level có dự đoán tốt hơn biến cho biến nội sinh trong mô hình, thậm chí khi chuỗi dữ liệu có tác động dai dẳng.

\subsection{Kiểm định kết quả ước luộng theo phương pháp GMM}

Kiểm định Sargan (hay kiểm định Hansen) sẽ được sử dụng. Kiểm định Sargan/Hansen xác định tính phù hợp của các biến công cụ trong mô hình GMM. Đây là kiểm định ràng buộc xác định quá mức (over-identifying restrictions) hay kiểm tra sự phù hợp của biến công cụ. 
Kiểm định Arellano - Bond (AR) được đề xuất bởi Arellano và Bond (1991) để kiểm tra tính chất tự tương quan của phương sai sai số mô hình GMM ở dạng sai phân bậc 1. Do đó, chuỗi sai phân khảo sát mặc nhiên có tương quan bậc $1, \operatorname{AR}(1)$ nên kết quả kiểm định được bỏ qua. Tương quan bậc $2, \mathrm{AR}(2)$ để phát hiện hiện tượng tự tương quan của phần dư ở bậc 2 . Giả thuyết $\mathrm{H} 0$ của kiểm định Arellano - Bond là không có tự tương quan bậc 2 cho phần dư và vì thế giá trị $\mathrm{P}$-value của kiểm định $\mathrm{AR}(2)$ càng lớn thể hiện không có tự tương quan bậc 2 cho phần dư.

\section{Kết quả và bình luận}

\subsection{Thống kê mô tả dũ liệu nghiên cứu của các biến giai đoạn 2008-2018}

\section{Bảng 2}

Thống kê mô tả biến giai đoạn 2008-2018

\begin{tabular}{lcccc}
\hline \multicolumn{1}{c}{ Biến } & Độ lệch chuẩn & Giá trị TB & Giá trị nhỏ nhất & Giá trị lớn nhất \\
\hline LEV & 0.2240 & 0.5108 & 0.0057 & 0.9929 \\
TOP5 & 0.1975 & 0.4848 & 0.05 & 0.88 \\
TVHDQTDL & 0.1053 & 0.3743 & 0 & 0.45 \\
QMBKS & 0.0848 & 1.1155 & 1.0986 & 1.6094 \\
QMHDQT & 0.1564 & 1.6913 & 1.6094 & 2.39790 \\
TTR & 22.9148 & 6.3810 & 0.01 & 677.36 \\
QMCT & 1.4823 & 26.9824 & 21.1540 & 33.2939 \\
ROA & 0.0911 & 0.0602 & -1.7393 & 0.0837 \\
TUOI & 0.6390 & 3.0111 & 1.0986 & 4.5326 \\
TSCD & 0.2132 & 0.2672 & 0.0008 & 0.9764 \\
\hline
\end{tabular}

LEV: Đòn bẩy tài chính, TOP5: Sở hữu tập trung, TVHDQTDL: Thành viên hội đồng quản trị độc lập, QMBKS: Quy mô ban kiểm soát, QMHDQT: Quy mô hội đồng quản trị, TTR: Tăng trưởng, QMCT: Quy mô công ty, TUOI: Tuổi của công ty, ROA: Lợi nhuận trên tổng tài sản

Nguồn: Dữ liệu được tính toán từ phần mềm Stata

Theo như số liệu thống kê trong Bảng 2, cho thấy biến phụ thuộc LEV có giá trị trung bình là $51,08 \%$. Chỉ số trung bình này không quá cao cũng không quá thấp cho thấy các doanh nghiệp có khả năng tự chủ tài chính không hoàn toàn phụ thuộc vào nguồn vốn vay, tuy nhiên chỉ số trung bình này cũng cho thấy các doanh nghiệp biết cách huy động vốn bằng hình thức đi vay. Giá trị nhỏ nhất của cấu trúc vốn là $0,57 \%$ và giá trị lớn nhất là $99,29 \%$ (Sở dĩ biến có dị biệt, nhưng chỉ tồn tại ở 1 số công ty trong mẫu theo những năm nhất định, tuy nhiên giá trị trung bình và độ lệch chuẩn của biến là đảm bảo nên số mẫu dữ liệu là phù hợp để nghiên cứu). Sở hữu tập trung cũng như sự đa dạng về sở hữu cổ phần có giá trị trung bình là 48,47\%, giá trị nhỏ nhất là $5 \%$ và lớn nhất là $88 \%$. Riêng thành viên hội đồng quản trị độc lập có giá trị nhỏ nhất là 0 vì những năm 2008,2009,2010, 2011 Nhà nước chưa có quy định về thành viên hội đồng quản trị độc lập, giá trị trung bình là 37,43\%. Quy mô ban kiểm soát có giá trị lớn nhất là 1.61 tương ứng với 5 người và giá trị nhỏ nhất là 1.10 tương ứng với 3 người theo quy định của Nhà nước. Quy mô hội đồng quản trị có giá trị trung bình là 1.69. Đối với các biến kiểm soát thì giá trị trung bình của tăng trưởng là 6.38 , quy mô công ty là 26.98 , tuổi của công ty là 3.01 , tỷ suất lợi nhuận trên tổng tài sản là 0.06 , tài sản cố định là 0.27 . 


\subsection{Kết quả kiểm định tính phù hợp của GMM}

\section{Kiểm định mô hình nội sinh}

Để kiểm định mô hình nội sinh tác giả sử dụng kiểm định Durbin-Wu Hausman test. Kết quả Bảng 3 cho thấy Chi2 $(3)=1197 ; \mathrm{p}=0,0000$, vì vậy có thể kết luận rằng có tính nội sinh trong mô hình $(P$.value $<\alpha$ ). Hiện tượng nội sinh làm cho các ước lượng thu được bằng phương pháp hồi quy tuyến tính cổ điển OLS, FEM hay REM không còn là ước lượng vững. Để kiểm tra tính phù hợp của biến nội sinh, ngoại sinh và biến công cụ, tác giả sử dụng kiểm định "Ivreg2".

\section{Bảng 3}

Kết quả kiểm định Durbin-Wu Hausman test

$\begin{array}{llrl}\text { Durbin (score) chi2 }(3) & =1197 \quad(\mathrm{p}=0.0000) \\ \text { Wu-Hausman } \mathrm{F}(3,5258) & =515.21 \quad(\mathrm{p}=0.0000)\end{array}$

Nguồn: Kết quả xử lý dữ liệu điều tra

Kết quả hồi quy Ivreg2- Kiểm định sụ̂ phù hợp của biến nội sinh, ngọ̣i sinh và biến công cụ

Kết quả tại Bảng 4 cho thấy Iv redundancy test có p.value $=0.000<\alpha$ chứng tỏ biến công cụ hoàn toàn phù hợp với mô hình và Sargan statistic có P.value là $0.5472>\alpha$ chứng tỏ biến công cụ là ngoại sinh. Kiểm định biến nội sinh "Endogeneity test" có P.value $=0.0000<$ $\alpha$ cho thấy mô hình bị nội sinh và biến bị nội sinh cũng phù hợp cho mô hình.

\section{Bảng 4}

Kiểm định sự phù hợp của biến công cụ và nội sinh "Ivreg2"

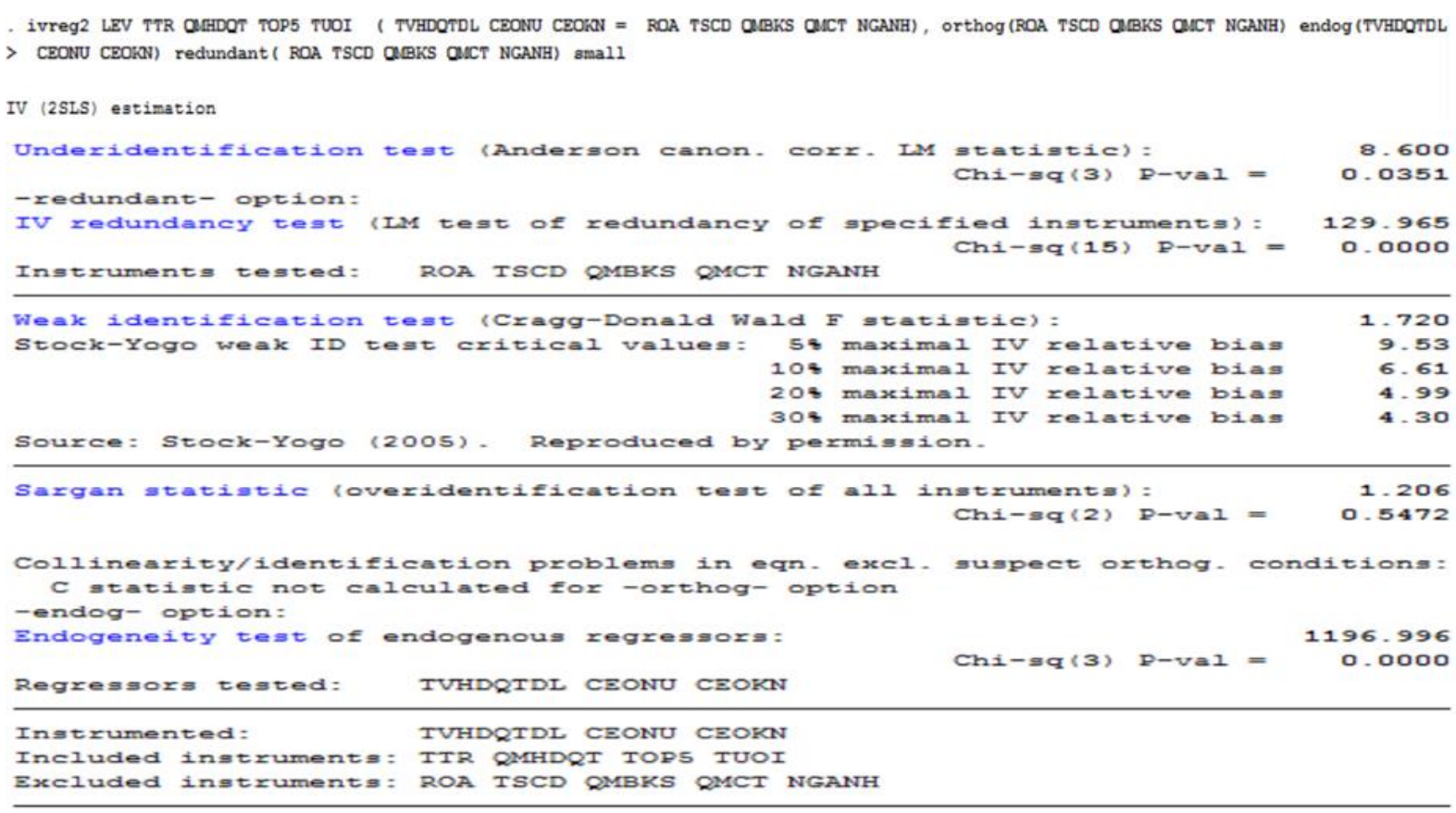

Nguồn: Kết quả phân tích từ Stata 


\subsection{Kết quả kiểm định phương sai sai số thay đổi, tụ tuơng quan và đa cộng tuyến}

\section{Bảng 5}

Kiểm định phương sai sai số thay đổi, tự tương quan và đa cộng tuyến

\section{Phương sai sai số thay đổi Tự tương quan Đa cộng tuyến}

\begin{tabular}{llc}
\hline Chi2 P-value $=0.000$ & $F(1,479)=354.198$ & VIF: 1.21 \\
& Prob $>F=0.0000$ &
\end{tabular}

Nguồn: Kết quả xử lý dữ liệu điều tra

Bảng 5 cho thấy mô hình có phương sai sai số thay đổi, có tự tương quan và mô hình không có đa cộng tuyến.

\subsection{Kết quả hồi quy của mô hình quản trị công ty và cấu trúc vốn}

\section{Bảng 6}

Kết quả hồi quy của mô hình quản trị công ty và cấu trúc vốn

\begin{tabular}{|c|c|c|c|c|c|c|}
\hline $\begin{array}{l}\text { Biến phụ } \\
\text { thuộc LEV }\end{array}$ & [1] & [2] & [3] & [4] & [5] & [6] \\
\hline L.LEV & $\begin{array}{c}0.88935 * \\
* * \\
(0.000) \\
\end{array}$ & $\begin{array}{c}0.88218 * \\
* * \\
(0.000)\end{array}$ & $\begin{array}{c}0.86828 * * \\
* \\
(0.000) \\
\end{array}$ & $\begin{array}{c}0.88023 * * \\
* \\
(0.000) \\
\end{array}$ & $\begin{array}{c}0.87390 * \\
* * \\
(0.000) \\
\end{array}$ & $\begin{array}{c}0.86177 * \\
* * \\
(0.000)\end{array}$ \\
\hline TOP5 & $\begin{array}{c}0.01289 \\
(0.133) \\
\end{array}$ & $\begin{array}{c}0.00880 \\
(0.450)\end{array}$ & $\begin{array}{c}0.00718 \\
(0.493)\end{array}$ & $\begin{array}{c}0.00867 \\
(0.448) \\
\end{array}$ & $\begin{array}{c}0.00908 \\
(0.357) \\
\end{array}$ & $\begin{array}{c}0.00091 \\
(0.937) \\
\end{array}$ \\
\hline CEOKN & & $\begin{array}{c}-0.05443 \\
(0.493)\end{array}$ & $\begin{array}{c}-0.04962 \\
(0.396)\end{array}$ & $\begin{array}{c}-0.05306 \\
(0.390) \\
\end{array}$ & $\begin{array}{c}-0.26879 \\
(0.650)\end{array}$ & $\begin{array}{c}-0.03790 \\
(0.591)\end{array}$ \\
\hline CEONU & & & $\begin{array}{c}-0.16137 \\
(0.647)\end{array}$ & $\begin{array}{c}-0.03692 \\
(0.342)\end{array}$ & $\begin{array}{c}-0.05629 \\
(0.259)\end{array}$ & $\begin{array}{c}-0.04572 \\
(0.220)\end{array}$ \\
\hline TVHDQTDL & & & & $\begin{array}{c}-0.17949 \\
(0.406)\end{array}$ & $\begin{array}{c}-0.09616 \\
(0.682)\end{array}$ & $\begin{array}{c}- \\
0.45933 * \\
* \\
(0.033) \\
\end{array}$ \\
\hline QMBKS & & & & & $\begin{array}{c}-0.00867 \\
(0.683)\end{array}$ & $\begin{array}{c}-0.00198 \\
(0.927)\end{array}$ \\
\hline QMHDQT & & & & & & $\begin{array}{c}- \\
0.04751 * \\
* * \\
(0.004)\end{array}$ \\
\hline TUOI & $\begin{array}{c}-0.00198 \\
(0.622)\end{array}$ & $\begin{array}{c}0.00005 \\
(0.988) \\
\end{array}$ & $\begin{array}{c}-0.00066 \\
(0.824)\end{array}$ & $\begin{array}{c}-0.00089 \\
(0.775)\end{array}$ & $\begin{array}{c}-0.00097 \\
(0.760)\end{array}$ & $\begin{array}{c}-0.00286 \\
(0.428)\end{array}$ \\
\hline QMCT & $\begin{array}{c}0.00280 \\
(0.429)\end{array}$ & $\begin{array}{c}0.00297 \\
(0.525) \\
\end{array}$ & $\begin{array}{c}0.00526 \\
(0.454) \\
\end{array}$ & $\begin{array}{c}0.00276 \\
(0.746) \\
\end{array}$ & $\begin{array}{c}0.00527 \\
(0.484) \\
\end{array}$ & $\begin{array}{c}0.01220 * \\
(0.071) \\
\end{array}$ \\
\hline
\end{tabular}




\begin{tabular}{|c|c|c|c|c|c|c|}
\hline $\begin{array}{c}\text { Biến phụ } \\
\text { thuộc LEV }\end{array}$ & [1] & [2] & [3] & [4] & [5] & {$[6]$} \\
\hline ROA & $\begin{array}{c}- \\
0.28687 * \\
* * \\
(0.000) \\
\end{array}$ & $\begin{array}{c}- \\
0.2893 * * \\
* \\
(0.000) \\
\end{array}$ & $\begin{array}{c}- \\
0.28690 * * \\
* \\
(0.000) \\
\end{array}$ & $\begin{array}{c}- \\
0.28430 * * \\
* \\
(0.000) \\
\end{array}$ & $\begin{array}{c}- \\
0.26184 * \\
* * \\
(0.000) \\
\end{array}$ & $\begin{array}{c}0.28909 * \\
* * \\
(0.000)\end{array}$ \\
\hline TSCD & $\begin{array}{c}- \\
0.02344 * \\
* \\
(0.015)\end{array}$ & $\begin{array}{c}- \\
0.02299 * \\
* \\
(0.013)\end{array}$ & $\begin{array}{c}- \\
0.02435^{* *} \\
(0.012)\end{array}$ & $\begin{array}{c}- \\
0.02455^{* *} \\
(0.015)\end{array}$ & $\begin{array}{c}- \\
0.02819 * \\
* * \\
(0.005)\end{array}$ & $\begin{array}{c}-0.01984 * \\
(0.081)\end{array}$ \\
\hline TTR & $\begin{array}{l}6.32000 \\
(0.956)\end{array}$ & $\begin{array}{l}-7.3300 \\
(0.942)\end{array}$ & $\begin{array}{c}-0.00002 \\
(0.868)\end{array}$ & $\begin{array}{c}-0.00003 \\
(0.852)\end{array}$ & $\begin{array}{c}-0.00003 \\
(0.783)\end{array}$ & $\begin{array}{l}5.79000 \\
(0.967)\end{array}$ \\
\hline NGANH & $\begin{array}{c}-0.00001 \\
(0.978)\end{array}$ & $\begin{array}{c}-0.00016 \\
(0.780)\end{array}$ & $\begin{array}{c}-0.00017 \\
(0.767)\end{array}$ & $\begin{array}{c}-0.00018 \\
(0.764)\end{array}$ & $\begin{array}{c}-0.00023 \\
(0.682)\end{array}$ & $\begin{array}{c}-0.00029 \\
(0.662)\end{array}$ \\
\hline Số quan sát & 4775 & 4775 & 4775 & 4775 & 4775 & 4775 \\
\hline Số nhóm & 480 & 480 & 480 & 480 & 480 & 480 \\
\hline $\begin{array}{l}\text { Số biến } \\
\text { công cụ }\end{array}$ & 90 & 78 & 84 & 80 & 66 & 96 \\
\hline F test - P.value & 0.000 & 0.000 & 0.000 & 0.000 & 0.000 & 0.000 \\
\hline $\begin{array}{l}\text { AR(1) test - } \\
\text { P.value }\end{array}$ & 0.000 & 0.000 & 0.000 & 0.000 & 0.000 & 0.000 \\
\hline $\begin{array}{l}\mathrm{AR}(2) \text { test - } \\
\text { P.value }\end{array}$ & 0.918 & 0.844 & 0.875 & 0.824 & 0.912 & 0.773 \\
\hline $\begin{array}{c}\text { Hansen test - } \\
\text { P.value }\end{array}$ & 0.331 & 0.188 & 0.153 & 0.133 & 0.710 & 0.472 \\
\hline
\end{tabular}

Ghi chú: Kết quả hồi quy theo phương pháp Sys-GMM với biến phụ thuộc LEV (Đòn bẩy tài chính) Sở hũu tập trung(TOP5), Quy mô hội đồng quản trị (QMHDQT), Quyền kiêm nhiệm (CEOKN), Quy mô của ban kiểm soát (QMBKS), Nữ tổng giám đốc điều hành (CEONU), Thành viên hội đồng quản trị độc lập (TVHDQTDL) Quy mô công ty (QMCT), Tăng trương(TTR), Độ tuổi công ty (TUOI), Tỷ suất sinh lọi trên tổng tài sản (ROA), Tài sản cố đinh (TSCD)

***, **, * đại diện cho mức ý nghĩa thống kê $1 \%, 5 \%$ và $10 \%$. Giá trị trong ngoặc đơn là P.value.

Nguồn: Kết quả phân tích từ Stata

\section{Thảo luận kết quả ước lự̣ng}

Hệ số của thành viên hội đồng quản trị độc lập (TVHDQTDL) trong cột 6 Bảng 6 bằng (0.45933) với mức ý nghĩa $5 \%$. Kết quả mang dấu âm tương đồng với nghiên cứu của Umawadee và cộng sự (2017). Tuy nhiên, kết quả này lại trái ngược với giả thuyết đưa ra. Như vậy có thể thấy số lượng các thành viên hội đồng quản trị độc lập tại các công ty niêm yết tại Việt Nam chưa phát huy tác dụng so với mong đợi của Nghị định 71/2017/NĐ-CP. Các thành viên độc lập phải là các chuyên gia trong từng lĩnh vực, có thể phát huy những thế mạnh chuyên môn trong việc kiểm soát việc đưa ra các quyết định về những khoản vay và giám sát việc thực hiện quyết định của ban điều hành. Phải là những người có uy tín, có kiến thức, kinh nghiệm và địa vị xã hội và nhìn nhận dưới góc độ lợi ích để thực hiện chứ không phải là tuân thủ pháp luật cho vấn đề này. 
Hệ số của quy mô hội đồng quản trị trong cột 6 Bảng 6 bằng (-0.04751) với mức ý nghĩa $1 \%$. Quy mô hội đồng quản trị càng lớn thì cấu trúc vốn của doanh nghiệp càng thấp, điều này trái ngược với giả thuyết đưa ra. Tuy nhiên, kết quả này cũng ủng hộ quan điểm của Robert và Rabih (2018), Berger và cộng sự (1997). Theo điều 149 trong luật doanh nghiệp 2004, hội đồng quản trị là cơ quan quản lý công ty, có toàn quyền nhân danh công ty để quyết định, thực hiện các quyền và nghĩa vụ của công ty không thuộc thẩm quyền của Đại hội đồng cổ đông. Khi thực hiện chức năng, quyền và nghĩa vụ của mình, Hội đồng quản trị tuân thủ đúng quy định của pháp luật, Điều lệ công ty và nghị quyết của Đại hội đồng cổ đông. Trong trường hợp nghị quyết do Hội đồng quản trị thông qua trái với quy định của pháp luật hoặc Điều lệ công ty gây thiệt hại cho công ty thì các thành viên tán thành thông qua nghị quyết đó phải cùng liên đới chịu trách nhiệm cá nhân về nghị quyết đó và phải đền bù thiệt hại cho công ty, thành viên phản đối thông qua nghị quyết nói trên được miễn trừ trách nhiệm. Vì vậy khi quyết định những khoản vay nào hội đồng quản trị rất cân nhắc để bảo đảm sự an toàn cho công ty và cho cả cá nhân của mình vì thế quy mô hội đồng quản trị có mối tương quan âm với cấu trúc vốn của doanh nghiệp.

Hệ số quy mô công ty (QMCT) ở Bảng 6, cột 6 cho thấy hệ số hồi quy của QMCT bằng 0.01220 với mức ý nghĩa $10 \%$. Quy mô công ty càng lớn mức độ sử dụng đòn bẩy càng cao, kết quả này tương đồng với các nghiên cứu của Robert và Rabih (2018); Buvanendra và cộng sự (2017). Các công ty lớn cần một lượng tiền lớn để mở rộng thị trường, chi nhánh mới cũng như đầu tư vào trang thiết bị hiện đại, mở rộng sản xuất kinh doanh, đa dạng hóa danh mục đầu tư, nhập công nghệ hiện đại và đào tạo nguồn nhân lực hiệu quả hơn, ... chính vì vậy một trong những cách mà các doanh nghiệp lớn đang làm chính là vay nợ.

Xem xét mức độ tác động của lợi nhuận trên tổng tài sản (ROA) ở Bảng 6 , cột 6 cho thấy hệ số lợi nhuận bằng $(-0.28909)$ và có mức ý nghĩa thống kê $1 \%$. Nghĩa là lợi nhuận trên tổng tài sản làm giảm cấu trúc vốn của công ty. Kết quả tương đồng với nghiên cứu của Mai và Truong (2018). Khi các doanh nghiệp có tỷ lệ lợi nhuận trên tổng tài sản cao thì họ không cần phải đi vay từ các tổ chức tín dụng hoặc nhà đầu tư, họ có thể phát triển công ty theo hướng kêu gọi đầu tư hoặc phát hành vốn cổ phần hơn là phát hành nợ. Do đó, các doanh nghiệp sẽ giảm áp lực trả lãi vay cũng như các khoản vay.

Hệ số của tài sản cố định (TSCD) ở Bảng 6, cột 6 bằng (-0.0984) với mức ý nghĩa thống kê $10 \%$. Đầu tư tài sản cố định có tác động ngược chiều với cấu trúc vốn. Để bắt đầu cho hoạt động sản xuất kinh doanh, đầu tư tài sản cố định là bắt buộc. Các doanh nghiệp ít khi mạo hiểm đầu tư vào tài sản cố định khi doanh nghiệp chưa có lãi hoặc chưa chắc việc kinh doanh sẽ tạo ra lợi nhuận nên họ không mạo hiểm đầu tư vào tài sản cố định bằng hình thức đi vay. Bên cạnh đó các công ty khi mở rộng hoạt động kinh doanh họ thường tính toán rất kỹ về khoản đầu tư ban đầu.

\section{Kết luận và hàm ý chính sách}

\subsection{Kết luận}

Kết quả cho thấy một số biến tác động đến cấu trúc vốn như thành viên hội đồng quản trị độc lập (TVHDQTDL), quy mô hội đồng quản trị (QMHDQT), tỷ suất lợi nhuận trên tổng 
tài sản (ROA), tài sản cố định (TSCD) tác động âm và có ý nghĩa thống kê với cấu trúc vốn. Quy mô công ty (QMCT) tác động dương với cấu trúc vốn. Riêng TOP5, CEOKN, QMBKS, CEONU, TTR, TUOI là không có tác động với cấu trúc vốn của doanh nghiệp.

\subsection{Hàm ý chính sách}

Thứ nhất, khi thực hiện chức năng, quyền và nghĩa vụ của mình, Hội đồng quản trị phải tuân thủ đúng quy định của pháp luật, Điều lệ công ty và nghị quyết của Đại hội đồng cổ đông để bảo đảm sự an toàn cho công ty. Và để thiết lập một cấu trúc HĐQT hoàn hảo cần xác định các loại thành viên HĐQT cần thiết theo mục tiêu của doanh nghiệp. Do đó, các công ty phải thường xuyên xem xét lại các kỹ năng cần có cho thành viên HĐQT và so sánh chúng với hồ sơ của các thành viên HĐQT. Những kỹ năng mềm và tính cách của các thành viên HĐQT cũng được xem xét vì chúng góp phần trong việc thiết lập một HĐQT phù hợp. Các doanh nghiệp nên cân nhắc trong các quyết định tuyển chọn, bổ nhiệm nhân sự cấp cao, đặc biệt là thành viên hội đồng quản trị. Bên cạnh đó, các doanh nghiệp cần hoàn thiện quy chế quản trị công ty, đảm bảo công ty được định hướng, điều hành và giám sát tốt, phục vụ lợi ích chính đáng của cổ đông và các bên liên quan.

Thú hai, ở Việt Nam, khi thị trường vốn phát triển và tạo ra những kênh đầu tư hấp dẫn cho công chúng thì số lượng thành viên HĐQT độc lập càng trở nên cần thiết. Hiện chưa quy định trách nhiệm giám sát việc bổ nhiệm các thành viên độc lập. Vì vậy, nên các thành viên Hội đồng quản trị độc lập phải có sự độc lập nhất định đối với công ty không liên quan về tài sản với công ty để tạo ra sự khách quan, vô tư trong quá trình hoạt động.

Các công ty nên đưa ra những tiêu chuẩn cao hơn về trình độ chuyên môn vì trình độ và kiến thức chuyên môn của họ giúp công ty đạt hiệu quả cao trong những quyết định về các khoản vay. Thành viên hội đồng quản trị phải là những người có uy tín và rất sợ mất uy tín của mình trước công chúng, trước mọi người. Họ phải là những người có kiến thức tốt, chuyên nghiệp trong lĩnh vực quản trị.

Thư ba, Luật Bình đẳng giới năm 2006 quy định các biện pháp thúc đẩy bình đẳng giới phải là các biện pháp nhằm đảm bảo bình đẳng giới thực chất và yêu cầu lồng ghép vấn đề bình đẳng giới trong xây dựng các văn bản quy phạm pháp luật nhằm thực hiện các mục tiêu bình đẳng giới. Bình đẳng giới trong lĩnh vực kinh tế cũng là một quy định của Luật này. Các trở ngại chung mà các nữ tổng giám đốc điều hành gặp phải như cân bằng công việc kinh doanh và gia đình (giữ gìn hạnh phúc gia đình, chăm lo con cái), những hạn chế trong quan hệ đối tác và mạng lưới kinh doanh (giao lưu). Nếu những vấn đề này không được giải quyết thấu đáo thì sẽ làm giảm tiềm năng và hiệu quả của các doanh nghiệp này đối với tăng trưởng kinh tế xã hội. Để làm được như vậy thì phụ nữ phải liên tục tự trau dồi kiến thức, biết cách cân bằng giữa công việc và gia đình.

Thú $\boldsymbol{t u}$, bên cạnh đó việc mở rộng quy mô công ty và vay để đầu tư tài sản cố định cũng là điều mà các công ty nên xem xét kỹ lưỡng trước khi vay vốn, trong trường hợp công ty không tạo ra lợi nhuận việc trả lãi cao cho vấn đề này cũng là vấn đề rất đáng lo ngại. Vì vậy cần phải có sự tính toán và cân nhắc sự thiệt hại từ vấn đề vay vốn này. 


\section{Tài liệu tham khảo}

Adams, R., \& Mehran, H. (2003). Is corporate governance different for bank holding companies? Economic Policy Review, 9, 123-142.

Al-Najjar, B., \& Taylor, P. (2008). The relationship between capital structure and ownership structure: New evidence from Jordanian panel data. Managerial Finance, 34(12), 919933.

Anderson, R. C., Mansi, S. A., \& Reeb, D. M. (2004). Board characteristics, accounting report integrity, and the cost of debt. Journal of Accounting and Economics, 37(3), 315-342.

Arellano, M., \& Bond, S. (1991). Some tests of specification for panel data: Monte Carlo evidence and an application to employment equations. Review of Economic Studies, 58(2), 277-297.

Berger, P. G., Ofek, E. L. I., \& Yermack, D. L. (1997). Managerial entrenchment and capital structure decisions. Journal of Finance, 52, 1411-1438.

Blundell, R., \& Bond, S. (1998). Initial conditions and moment restrictions in dynamic panel data models. Journal of Econometrics, 87, 115-143.

Buvanendra, S., Sridharan, P., \& Thiyagarajan, S. (2017). Firm characteristics, corporate governance and capital structure adjustments: A comparative study of listed firms in Sri Lanka and India. IIMB Management Review, 29(4), 245-258. doi:10.1016/j.iimb.2017.10.002

Caramanis, C., \& Lennox, C. (2008). Audit effort and earnings management. Journal of Accounting and Economics, 45(1), 116-138.

Caramanolis-Cotelli, B. (1995). External and internal corporate control mechanism and the role of.the board of directors: A review of the literature (Working Paper No. 9606).

Chancharat, N., Krishnamurti, C., \& Tian, G. (2012). Board structure and survival of new economy IPO firms. Corporate Governance: An International Review, 20(2), 144-163.

Chen, Z., Cheung, Y.-L., Stouraitis, A., \& Wong, A. W. S. (2005). Ownership concentration, firm performance, and dividend policy in Hong Kong. Pacific-Basin Finance Journal, $13(4), 431-449$.

Claessens, S., \& Fan, J. P. H. (2002). Corporate governance in Asia: A survey. International Review of Finance, 3(2), 71-103.

Detthamrong, U., Chancharata, N., \& Vithessonthi, C. (2017). Corporate governance, capital structure and firm performance: Evidence from Thailand. Research in International Business and Finance, 42, 689-709.

Dey, A., Engel, E., \& Liu, X. (2011). CEO and board chair roles: To split or not to split? Journal of Corporate Finance, 17(5), 1595-1618. 
Heng, T. B., Azrbaijani, S., \& San, O. T. (2012). Board of directors and capital structure: Evidence from leading Malaysian companies. Journal Asian Social Science, 8(3), 123136.

Huang, M., Li, P., Meschke, F., \& Guthrie, J. P. (2015). Family firms, employee satisfaction, and corporate performance. Journal of Corporate Finance, 34, 108-127. doi:10.1016/j.jcorpfin.2015.08.002

Jensen, M. C. (1986). Agency costs of free cash flow, corporate finance, and takeovers. The American Economic Review, 76(2), 323-329.

Mai, T. P. T., \& Truong, N. T. V. (2018). Tác động của quản trị doanh nghiệp đến cấu trúc vốn của công ty [The impact of corporate governance on the company's structural capital]. Tạp chí Tài chính co quan thông tin của Bộ Tài chính, 60(2), 61-63.

Nadeem, A. S., \& Zongjun, W. (2011). Determinants of capital structure: An empirical study of firms in manufacturing industry of Pakistan. Managerial Finance, 2, 117-133.

Robert, K., \& Rabih, M. (2018). Firm age, corporate governance, and capital structure choices. Journal of Corporate Finance, 48(C), 597-614.

Ross, S. A. (1973). The economic theory of agency: The principal's problem. The American Economic Review, 2, 134-139.

Ross, S. A., Westerfield, R. W., \& Jaffe, J. (2005). Corporate finance (7th ed.). New York, NY: McGraw-Hill.

Shafana, M. A. C. N. (2016). Board of directors' characteristics impact on capital structure decisions: Evidence from Top 50 turnover non-financial companies listed on the Colombo Stock exchange. International Journal of Science Research, 5(10), 79-86.

Shleifer, A., \& Vishny, R. W. (1997). A survey of corporate governance. Journal of Finance, 2, 737-783.

Simpson, W. G., \& Gleason, A. E. (1999). Board structure, ownership, and financial distress in banking firms. International Review of Economics \& Finance, 8(3), 281-292.

Strøm, R. Ø., D’Espallier, B., \& Mersland, R. (2014). Female leadership, performance, and governance in microfinance institutions. Journal of Banking \& Finance, 42(1), 60-75.

Suto, M. (2003). Capital structure and investment behaviour of Malaysian firms in the 1990: A study of corporate governance before the crisis. Corporate Governance: An International Review, 11(1), 25-39.

Umawadee, D., Nongnit, C., \& Chaiporn, V. (2017). Corporate governance, capital structure and firm performance: Evidence from Thailand. Research in International Business and Finance, 42, 689-709.

Wiwattanakantang, Y. (2001). Controlling shareholders and corporate value: Evidence from Thailand. Pacific-Basin Finance Journal, 9(4), 323-362.

Zelechowski, D. D., \& Bilimoria, D. (2004). Characteristics of women and men corporate inside directors in the US. Corporate Governance: An International Review, 12(3), 337-342. 